\title{
Review Article \\ Policy to Promote Technology Transfer: Experiences from China and Lessons for Vietnam
}

\author{
Nguyen Quoc Huy ${ }^{1, *}$, Tran Hau Ngoc 2 , Nguyen Huu Xuyen ${ }^{3}$ \\ ${ }^{1}$ Hanoi Architectural University, Km 10 Nguyen Trai, Thanh Xuan, Hanoi, Vietnam \\ ${ }^{2}$ Vietnam Centre for Science and Technology Evaluation, 39 Tran Hung Dao, Hoan Kiem, Hanoi, Vietnam \\ ${ }^{3}$ National Institute of Patent and Technology Exploitation, 39 Tran Hung Dao, Hoan Kiem, Hanoi, Vietnam
}

Received 02 July 2020

Revised 30 October 2020; Accepted 30 October 2020

\begin{abstract}
China used to be considered as the world's factory, but up to now, China's technological capacity has made positive changes, showing the most clearly in decoding and mastering high technology. To achieve these achievements, the efforts of Chinese enterprises are not enough as they need support from the Government's policies to acquire and master technology through technology transfer. This paper focuses on researching policies to support China's technology transfer, thereby drawing lessons that are suitable to Vietnam's conditions in the context of a strong fourth industrial revolution.
\end{abstract}

Keywords: Support policies, technology transfer.

\footnotetext{
${ }^{*}$ Corresponding author.

Email address: nguyenquochuy@gmail.com
}

https://doi.org/10.25073/2588-1116/vnupam.4243 


\title{
Chính sách thúc đẩy chuyển giao công nghệ: Kinh nghiệm của Trung Quốc và bài học cho Việt Nam
}

\author{
Nguyen Quoc Huy ${ }^{1, *}$, Tran Hau Ngoc ${ }^{2}$, Nguyen Huu Xuyen ${ }^{3}$ \\ ${ }^{1}$ Truò̀ng Đại học Kiến trúc Hà Nội, km 10 Nguyễn Trãi, Thanh Xuân, Hà Nội, Việt Nam \\ ${ }^{2}$ Viện Đánh giá Khoa học và Định giá Công nghệ, 39 Trần Hung Đạo, Hoàn Kiếm, Hà Nội, Việt Nam \\ ${ }^{3}$ Viện Nghiên cứu Sáng chế và Khai thác Công nghệ, 39 Trần Hung Đạo, Hoàn Kiếm, Hà Nội, Việt Nam \\ Nhận ngày 02 tháng 07 năm 2020 \\ Chỉnh sửa ngày 30 tháng 10 năm 2020; Chấp nhận đăng ngày 30 tháng 10 năm 2020
}

\begin{abstract}
Tóm tắt: Trung Quốc từng được coi là công xưởng của thế giới, tuy nhiên đến nay trình độ, năng lực công nghệ của Trung Quốc đã có những chuyển biến tích cực, biểu hiện rõ nhất trong việc nghiên cứu và triển khai, giải mã và làm chủ công nghệ cao. Để đạt được những thành tựu này, sự nỗ lực của các doanh nghiệp Trung Quốc là quan trọng nhưng chưa đủ mà cần có sự hố trợ từ chính sách của Chính phủ trong việc tiếp thu, làm chủ công nghệ thông qua chuyển giao công nghệ. Bài báo này tập trung nghiên cứu chính sách hỗ trợ chuyển giao công nghệ của Trung Quốc, từ đó rút ra các bài học phù hợp với điều kiện của Việt Nam trong bối cảnh cuộc cách mạng công nghiệp lần thứ tư đang diễn ra mạnh mẽ.
\end{abstract}

Tù khóa: Chính sách hỗ trợ, chuyển giao công nghệ.

\section{Chính sách hỗ trọ chuyển giao công nghệ của Trung Quốc}

Trung Quốc đã làm chủ và chế tạo được tàu vũ trụ có người lái, siêu máy tính, các nhà máy nhiệt điện đốt than, lò phản ứng hạt nhân, các tuyến truyền tải điện, động cơ hiệu suất cao, thiết bị năng lượng tái tạo và tàu hỏa cao tốc của Trung Quốc được đánh giá là tiên tiến và đã tạo nên sự cạnh tranh với các loại công nghệ của Mỹ và các nước đang phát triển. Hiện nay, Việt Nam và Trung Quốc đã có những hợp tác song phương nhất định trong hoạt động khoa học và công nghệ nói chung, chuyển giao công nghệ nói riêng. Theo Bộ Khoa học và Công nghệ (2019), hợp tác về khoa học và công nghệ $(\mathrm{KH} \& \mathrm{CN})$ giữa Việt Nam và Trung Quốc trong giai đoạn 2016-2018

\footnotetext{
*Corresponding author.

Email address: nguyenquochuy@gmail.com
}

https://doi.org/10.25073/2588-1116/vnupam.4243 đã có nhiều tiến triển hơn so với giai đoạn những năm 2012-2016 [1]. Đặc biệt, Chương trình đối tác hợp tác KH\&CN Trung Quốc - ASEAN (Chương trình STEP) được khởi động từ năm 2013, Chương trình được xây dựng để triển khai các hoạt động hợp tác giữa Trung Quốc và các nước ASEAN, trong đó có Việt Nam với bốn nội dung chính: Phòng Thí nghiệm liên hợp ASEAN - Trung Quốc; Trung tâm Dịch vụ dữ liệu viễn thám ASEAN - Trung Quốc; Trung tâm Chuyển giao công nghệ ASEAN - Trung Quốc; Nhà khoa học trẻ tiêu biểu đến làm việc tại Trung Quốc. Thực tế, với những kết quả trong lĩnh vực chuyển giao công nghệ mà Trung Quốc đạt được một phần là do các chính sách hỗ trợ, ưu đãi cho việc tiếp nhận, làm chủ công nghệ thông qua chuyển giao công nghệ của Trung Quốc đã có 
những tác động lan tỏa và đã mang lại hiệu quả tích cực, cụ thể:

Thư nhất, ưu tiên cho nghiên cứu và triển khai công nghệ kể cả trong giai đoạn gặp khó khăn nhât. Năm 1949, Nhà nước Cộng hòa nhân dân Trung Hoa ra đời, vào thời điểm này, Chính phủ Trung Quốc đã kế thừa khoảng 40 cơ quan nghiên cứu và phát triển với 50.000 cán bộ nghiên cứu, trong đó có khoảng 600 người là nghiên cứu chuyên môn sâu và nghiên cứu phát triển công nghệ. Những năm 50 của thế kỷ 20 , kinh tế Trung Quốc gặp nhiều khó khăn nhưng Chính phủ Trung Quốc vẫn ưu tiên kinh phí cho hoạt động nghiên cứu khoa học và phát triển công nghệ. Nhận thức được tầm quan trọng của công nghệ trong việc phát triển đất nước, Trung Quốc đã có những sách lược trong việc nhập khẩu công nghệ, làm chủ công nghệ để đưa Trung Quốc phát triển. Chi phí cho nghiên cứu và phát triển công nghệ của Trung Quốc năm 1960 đã tăng lên 60 lần so với năm 1952. Kế hoạch 5 năm lần thứ X (2001-2005) của Trung Quốc tiếp tục khẳng định, $\mathrm{KH} \& \mathrm{CN}$ là lực lượng sản xuất cao nhất do đó cần nâng cao năng lực nội sinh công nghệ của đất nước và khả năng chuyển hóa năng lực đó thành năng suất lao động, xây dựng kinh tế dựa vào tiến bộ $\mathrm{KH} \& \mathrm{CN}$ và hiệu quả lao động [2]. Theo đó các ưu tiên chiến lược đối với KH\&CN là đẩy mạnh nâng cấp công nghệ trong ngành công nghiệp, tăng cường năng lực đổi mới $\mathrm{KH} \& \mathrm{CN}$. Để thực hiện mục tiêu nêu trên Chính phủ Trung Quốc theo đuổi ba biện pháp chính sách: Cải thiện nghiên cứu và triển khai trong khu vực doanh nghiệp và phát triển các ngành công nghiệp công nghệ cao; cải tổ hệ thống KH\&CN và tối ưu hóa sự phân bổ nguồn lực cho nghiên cứu và triển khai; tăng cường quản lý, bảo vệ quyền sở hữu trí tuệ và đẩy mạnh cung cấp tài chính cho nghiên cứu và triển khai; phát triển các thị trường vốn và cho phép khai thác các phương thức có hiệu quả cung cấp tài chính cho các ngành công nghiệp công nghệ cao và các doanh nghiệp công nghệ [3].

Thư hai, nhập khẩu công nghệ tù các nước xã hội chủ nghĩa và thúc đẩy phát triển công nghệ trong các ngành công nghiệp nặng. Những năm 50, Trung Quốc thực hiện kế hoạch 5 năm lần thứ nhất để phát triển kinh tế và nhập khẩu công nghệ của Liên Xô (cũ) với quy mô lớn, Trung Quốc đã ưu tiên phát triển các ngành công nghiệp nặng, chú trọng tới phát triển công nghệ trong lĩnh vực cơ khí chế tạo. Từ năm 1950 đến 1959 , đã có 150 quy trình công nghệ được viện trợ từ Liên Xô, bao gồm từ 400-500 hạng mục công nghệ. Những công nghệ then chốt gồm cơ khí động lực, cơ khí chế tạo và đồ dùng cho quân sự, sự viện trợ công nghệ của các nước xã hội chủ nghĩa là kênh nhập khẩu công nghệ quan chính của Trung Quốc vào thập kỷ 50 . Bởi khi đó, các nước tây Âu thực hiện chính sách cấm xuất nhập khẩu đối với Trung Quốc, cho nên Trung Quốc chỉ có thể nhập khẩu công nghệ từ Liên Xô cũ và các nước xã hội chủ nghĩa ở Đông Âu. Những công nghệ được đưa sản xuất không những làm tăng sức mạnh công nghiệp của Trung Quốc mà còn là nền tảng để phát triển công nghệ sau này. Do đó, trong giai đoạn này Trung Quốc đã thành công trong việc làm chủ công nghệ, nâng cao năng lực công nghệ quốc gia thông qua nhập khẩu công nghệ từ nước ngoài, đặc biệt là Liên Xô (cũ). Vào những năm 60, quan hệ Liên Xô cũ và Trung Quốc trở nên xấu đi, Liên Xô đã hạn chế, thậm chí ngừng chuyển giao công nghệ cho Trung Quốc [4]. Vì thế chiến lược của Trung Quốc buộc phải thay đổi, từ chỗ học hỏi Liên Xô sang tự lực phát triển công nghệ, do đó Trung Quốc đã tổ chức lại hệ thống KH\&CN trong nước và tự mình giải quyết các vấn đề khó khăn về công nghệ.

Thư ba, tăng cường nhập khẩu công nghệ tì Nhật Bản và các nuớc tây Âu để phát triển kinh tế. Từ năm 1963, Trung Quốc đã nhập khẩu các thiết bị, công nghệ từ Nhật Bản và các nước Tây Âu, những công nghệ trọng điểm gồm các công nghệ trong lĩnh vực luyện kim, hóa dầu, công nghiệp hóa học, dệt, cơ khí. Đã có 84 danh mục công nghệ được đưa vào trong giai đoạn này, quy mô không lớn như lần trước nhưng những danh mục được nhập khẩu là những thiết bị, công nghệ tiên tiến, đóng vai trò quan trọng đối với việc nâng cao năng lực sản xuất và tích lũy công nghệ của Trung Quốc vào thời điểm đó. Do ảnh hưởng của cuộc Cách mạng Văn hóa năm 1966, Trung Quốc đã ngừng nhập khẩu công nghệ. Từ 1966 
đến 1972, Trung Quốc bị cô lập khỏi dòng chảy phát triển công nghệ của thế giới, do đó việc nhập khẩu công nghệ mới cũng rơi vào tình trạng khó khăn. Sau năm 1972, Trung Quốc được thừa nhận và tham gia vào tổ chức của Liên Hiệp Quốc, quan hệ giữa Trung Quốc với Mỹ, Nhật Bản, Tây Âu được cải thiện và Chính phủ Trung Quốc đầu tư 4,3 tỷ USD để nhập khẩu thiết bị, công nghệ mới. Giai đoạn 1973-1979 là giai đoạn nhập khẩu công nghệ và đưa nhanh vào áp dụng những công nghệ được nhập từ nước ngoài vào sản xuất, đặc biệt là những công nghệ, thiết bị cắt kim loại, công nghệ sản xuất phân bón hóa học cỡ lớn, công nghệ tơ sợi hóa học, công nghệ hóa dầu, công nghệ phát điện, công nghệ khai thác than tổng hợp $[3,6]$. Nhờ nhập khẩu những công nghệ mới trong thời kỳ này nên Trung Quốc đã cải thiện được tình hình sản xuất công nghiệp, xúc tiến phát triển một phần quan trọng các ngành sản xuất mới như công nghiệp cơ khí, kinh tế được phát triển, năng lực tiếp thu, làm chủ công nghệ nhập đã được cải thiện đáng kể.

Thư tu, nâng cao năng lục nội sinh công nghệ thông qua chuyển giao công nghệ. Bước vào thập kỷ 90 , Trung Quốc có nhiều thuận lợi trong việc nhập khẩu công nghệ quan trọng để phát triển đất nước. Các hình thức nhập khẩu công nghệ của Trung Quốc đã chuyển sang một hình thức mới, những công ty công nghệ lớn trên thế giới như AT\&T, MOTOROLA, Matsushita,... đều đã thành lập những cơ sở, hay các bộ phận nghiên cứu và triển khai tại Trung Quốc và các công ty này có khả năng đáp ứng nhu cầu công nghệ của nước này $[2,4]$. Nhờ những chính sách hợp lý về nhập khẩu công nghệ thông qua chuyển giao công nghệ, năng lực làm chủ công nghệ nhập, cùng với truyền thống sáng tạo của người Trung Quốc nên Trung Quốc đã xuất khẩu công nghệ sang các nước đang phát triển. Năm 1999, Hội nghị Đổi mới công nghệ toàn quốc đã được tổ chức và kể từ đó chính sách KH\&CN của Trung Quốc tập trung chủ yếu vào thực hiện ba mục tiêu chính sách: Tăng cường đồi mới công nghệ; phát triển công nghệ cao; hỗ trợ công nghiệp hóa nền kinh tế Trung Quốc.

Thư năm, hình thành và phát triển các loại quỹ tài chính để khuyển khich đổi mới và chuyển giao công nghệ. Để thúc đẩy hoạt động làm chủ, đổi mới công nghệ trong các doanh nghiệp, bên cạnh các chương trình quốc gia về phát triển ngành công nghiệp mũi nhọn, Trung Quốc đã tạo ra điều kiện để các doanh nghiệp nhỏ và vừa được hình thành, phát triển trong gần $1.000 \mathrm{khu}$ công nghiệp, khu công nghệ cao và đặc khu kinh tế. Nhằm hỗ trợ các doanh nghiệp làm chủ và liên tục đổi mới công nghệ thông qua chuyển giao công nghệ, Quỹ đổi mới công nghệ quốc gia Trung Quốc (Innofund) và các Quỹ công nghệ (Technofund) ở nhiều tỉnh, thành phố đã được thành lập. Năm 1993, Chính phủ Trung Quốc quyết định thành lập Quỹ đổi mới công nghệ quốc gia (China Innofund) và 5 năm sau đó cho phép các tỉnh, thành phố trực thuộc trung ương thành lập các Quỹ công nghệ. Quỹ tài trợ, hỗ trợ lãi suất vay cho các doanh nghiệp có dự án đầu tư làm chủ, đổi mới công nghệ trong các lĩnh vực công nghệ cao, công nghệ mới [5]. Sau khi chương trình phát triển khoa học và công nghệ của Trung Quốc được thông qua tại Đại hội lần thứ XV Đảng Cộng sản Trung Quốc, đã có nhiều tỉnh, thành phố trực thuộc trung ương thành lập Quỹ công nghệ với chức năng tài trợ, hỗ trợ lãi suất vay cho doanh nghiệp địa phương để triển khai các dự án chuyển giao, đổi mới công nghệ. Quỹ đổi mới công nghệ quốc gia và các Quỹ công nghệ tại các tỉnh, thành phố đã phối hợp chặt chẽ với các sàn giao dịch công nghệ của Trung Quốc để đẩy mạnh hoạt động kết nối, chuyển giao công nghệ. Cùng với đó năm 2016, phương án hành động thúc đẩy chuyển đổi thành tựu khoa học và công nghệ đã được Quốc vụ viện thông qua, theo đó Trung Quốc tăng cường sự hỗ trợ từ nguồn tài chính địa phương đối với việc khích lệ các địa phương xây dựng các quỹ định hướng đầu tư khởi nghiệp, quỹ chuyển hóa thành tựu khoa học và công nghệ, quỹ ứng dụng quyền sở hữu trí tuệ, quỹ tín dụng, quỹ đầu tư khởi nghiệp và khuyến khích nguồn vốn xã hội để tăng cường đầu tư, hỗ trợ chuyển đổi công nghệ trong các ngành sản xuất trọng điểm ở từng địa phương [1].

Thư sáu, thúc đẩy doanh nghiệp đổi mới sáng tạo để phát triển nền kinh tế. Đến nay, mô hình tăng trưởng kinh tế của Trung Quốc đã có 
sự thay đổi, chuyển biến theo hướng đổi mới sáng tạo và nỗ lực để tái cân bằng nền kinh tế từ xuất khẩu và đầu tư hướng tới chi tiêu của khu vực tư nhân. Vai trò của đổi mới sáng tạo ngày càng tăng cường, cụ thể Trung Quốc đã dành $1,98 \%$ GDP cho nghiên cứu và triển khai trong năm 2012, năm 2017 là 2,15\% và đến năm 2018 con số này đã lên tới $2,19 \%$ (Mức chi này gần tiệp cận với một số nước phát triển, ví dụ năm 2017 , Pháp đã chi $2,19 \%$ GDP, Đức $3,04 \%$ và Hoa Kỳ 2,79\%). Trong hoạt động chuyển giao và thương mại hóa công nghệ, năm 2013, Văn phòng Lập pháp của Hội đồng Nhà nước sửa đổi Luật Thúc đẩy chuyển giao thành tựu $\mathrm{KH} \& \mathrm{CN}$, qua đó đã làm cho số các liên minh chiến lược giữa các ngành công nghiệp, viện nghiên cứu, trường đại học cho đổi mới công nghệ tăng nhanh, mạnh trong những năm gần đây.

Trung Quốc đã sử dụng các khu trình diễn công nghệ, kết nối cung cầu công nghệ, đổi mới sáng tạo như một công cụ chính sách quan trọng để làm mũi nhọn dẫn đầu cho đổi mới sáng tạo, đặc biệt là đổi mới sáng tạo trong lĩnh vực cơ khí, chế biến, chế tạo [6]. Đến nay đã có nhiều khu trình diễn, kết nối công nghệ, điển hình có ba công viên khoa học được xây dựng tại Trung Quan Thôn (Bắc Kinh), Hồ Đông (Vũ Hán) và Trạm Giang (Thượng Hải). Các doanh nghiệp nằm trong các công viên này được hưởng chính sách ưu đãi và hỗ trợ công cho các hoạt động tiếp nhận, làm chủ công nghệ và đổi mới sáng tạo. Ngoài ra, Kế hoạch phát triển và đổi mới sáng tạo vùng Đồng bằng Châu Giang (2008 - 2020) hướng tới trở thành một trung tâm công nghệ, đổi mới sáng tạo trong khu vực châu Á - Thái Bình Dương cũng được Trung Quốc triển khai và đầu tư phát triển.

\section{Bài học cho Việt Nam về chính sách hỗ trọ chuyển giao công nghệ}

Nhìn lại quá trình tiếp nhận và tích lũy công nghệ của Trung Quốc thông qua chuyển giao công nghệ cho thấy, Trung Quốc đã hình thành các chiến lược, kế hoạch phát triển $\mathrm{KH} \& \mathrm{CN}$ Quốc gia phù hợp, trong đó nhấn mạnh tới hoạt động động hỗ trợ chuyển giao công nghệ trong từng giai đoạn phát triển của đất nước thông qua các chính sách phù hợp. Đây là những gợi ý có giá trị cho Việt Nam trong quá trình hình thành và thực thi chính sách thúc đầy chuyển giao công nghệ.

Thư nhất, nâng tầm vai trò của phát triển công nghệ đối với tăng trương kinh tế, thự sư coi công nghệ là động lực cho phát triển kinh tế, $x \tilde{a}$ hội. Hiện nay, trình độ, năng lực công nghệ và khả năng giải mã công nghệ của các doanh nghiệp Việt Nam còn thấp so với với một số nước trong khu vực, tỷ lệ nhóm ngành sử dụng công nghệ cao của Việt Nam chỉ đạt khoảng 20\% (tỷ lệ này của Thái Lan là $31 \%$, Malaysia là $51 \%$ ), trong khi tiêu chí để đạt trình độ công nghiệp hóa, hiện đại hóa là trên $60 \%$. Hơn nữa, tăng trưởng kinh tế của Việt Nam hiện vẫn dựa vào thâm dụng vốn, lao động, trong khi đó, nhiều nước trong khu vực có tỷ lệ đóng góp của nhân tố năng suất tổng hợp (TFP) vào tăng trưởng kinh tế đạt trên $50 \%$ như Thái Lan là $53 \%$, Hàn Quốc là $51,5 \%$, Trung Quốc là $52 \%$, trong khi đó Việt Nam mới chỉ đạt khoảng 40\% [7]. Do đó, việc tiếp tục hỗ trợ doanh nghiệp tiếp nhận, chuyển giao công nghệ để nâng cao trình độ, năng lực công nghệ là cần thiết, đặc biệt là năng lực tiếp thu, đồng hóa và làm chủ công nghệ. Các hoạt động này có sự gắn bó mật thiết với quá trình nghiên cứu để tạo ra những sản phẩm, quy trình mới, có tác động tác dụng trực tiếp đến vị thế, năng lực cạnh tranh của doanh nghiệp, cũng như ảnh hưởng tới tốc độ tăng trưởng và sự phát triển bền vững của quốc gia.

Thứ hai, thức đẩy hoạt động nhập khẩu công nghệ cao, công nghệ tiên tiến, công nghệ thân thiện với môi truoơng. Để thực hiện được hoạt động này, ngoài việc tạo môi trường pháp lý thuận lợi thì cần thiết phải xây dựng cơ sở dữ liệu công nghệ, chuyên gia đánh giá công nghệ để hỗ trợ doanh nghiệp trong quá trình lựa chọn công nghệ để tiếp nhận, chuyển giao. Cơ sở dữ liệu này sẽ hỗ trợ các doanh nghiệp, các nhà khoa học có thể tra cứu, tìm hiểu thông tin cần thiết công nghệ mà doanh nghiệp có nhu cầu, cũng như lựa chọn được các chuyên gia phù hợp với doanh nghiệp để doanh nghiệp có thể chủ động chia sẻ, 
trao đổi và hợp tác trong nghiên cứu, phát triển và làm chủ công nghệ. Cùng với đó là hình thành và nâng cao hiệu quả hoạt động của các tổ chức trung gian phục vụ cho chuyển giao công nghệ, hỗ trợ chuyển giao các kết quả nghiên cứu có tiềm năng ứng dụng thông qua văn phòng chuyển giao công nghệ (TTO), trung tâm đổi mới sáng tạo (innovation center), hoặc tạo khung khổ pháp lý để các tổ chức trung gian thành lập, hoạt động một cách bền vững và có hỗ trợ một phần kinh phí cho các tổ chức này phát triển.

Thú ba, tạo điều kiện thuận lợi cho doanh nghiệp hoc tập, tiếp thu công nghệ thông qua các $d u ̛$ án FDI. Để làm tốt điều này cần thúc đẩy hình thành bộ phận nghiên cứu và phát triển tại doanh nghiệp, đây có thể cói là một trong các hướng đi phù hợp với để từng bước nâng cao trình độ, năng lực đổi mới công nghệ của các doanh nghiệp trong thời gian tới. Tuy nhiên, trong quá trình hỗ trợ doanh nghiệp thì cần đảm bảo tuân thủ theo các quy định của pháp luật về chuyển giao công nghệ, đặc biệt là cơ chế bắt buộc đăng ký chuyển giao công nghệ từ nước ngoài vào Việt Nam, đồng thời cần tăng cường kiểm soát để hạn chế tình trạng chuyển giá, gian lận và tiếp nhận công nghệ thuộc danh mục cấm, hoặc hạn chể chuyển giao vào Việt Nam. Hơn nữa, để học tập và tiếp thu được hiệu quả thì nâng cao chất lượng nguồn nhân lực công nghệ. Đây là nội dung quan trọng được các quốc gia quan tâm và có các chương trình hành động cụ thể. Thực thế chất lượng và năng lực nguồn nhân lực trong các doanh nghiệp Việt Nam còn hạn chế, cùng với đó trình độ quản trị sản xuất đa phần chưa thích ứng được với cuộc cách mạng công nghiệp lần thứ tư [8]. Do đó, việc xây dựng, đào tạo đội ngũ chuyên gia, nhà khoa học đầu đàn và hình thành các nhóm nghiên cứu mạnh là cần thiết để thúc đẩy hoạt động chuyển giao, làm chủ công nghệ.

Thư tu, khuyến khich doanh nghiệp ứng dưng sáng chế, giải pháp hưu ich để nâng cao vị thể cạnh tranh trên thị truò̀ng. Việc xác lập được mối liên hệ giữa mục tiêu phát triển của doanh nghiệp với mục tiêu ứng dụng sáng chế, giải pháp hữu ích là yêu cầu cần thiết để đẩy nhanh tiến trình đổi mới, làm chủ công nghệ thông qua chuyển giao công nghệ. Hiện nay, Việt Nam có ít các sáng chế, giải pháp hữu ích được bảo hộ và khai thác, tốc độ đổi mới công nghệ dựa vào khai thác sáng chế, giải pháp hữu ích còn chậm. Trong khí đó, cuộc cách mạng công nghiệp lần thứ tư đang diễn ra mạnh mè̃, các sáng chế, công nghệ mới đã làm thay đổi cách thức, phương thức sản xuất, điều này đặt ra yêu cầu cần thiết phải đổi mới, làm chủ công nghệ và cập nhật xu thế công nghệ của thế giới. Thực tế cho thấy, để phát triển và nâng cao vị thế cạnh tranh, các nước đang phát triển, trong đó có Việt Nam thường bị ảnh hưởng bởi hai rào cản cơ bản, đó là rào cản về công nghệ và rào cản về thị trường. Các nước đang phát triển thường chưa thực sự có những quan hệ mật thiết với các nhà cung cấp công nghệ, các nhà sáng chế nước ngoài trong khi năng lực công nghệ của doanh nghiệp chưa cao; còn rào cản về tiếp cận thị trường nước ngoài, nhất là các thị trường khó tính vì thiếu năng lực marketing, vì chưa có thương hiệu nổi tiếng, vì không có mạng lưới phân phối. Do đó, việc khuyển khích doanh nghiệp ứng dụng sáng chế, giải pháp hữu ích để nâng cao vị thế cạnh tranh trên thị trường là cần thiết, qua đó không những khắc phục được rào cản về công nghệ mà còn khắc phục được rào cản về thị trường thông qua hoạt động đổi mới sáng tạo.

Thư năm, hỗ trọ doanh nghiệp đổi mới sáng tạo thông qua các chính sách ưu đãi về tín dụng, thuế. Việc đẩy mạnh đổi mới sáng tạo trong doanh nghiệp là cần thiết, do đó Nhà nước cần phải tạo điều kiện thuận lợi hơn nữa về mặt thủ tục, quy trình để hỗ trợ doanh nghiệp tiếp cận và sử dụng các chính sách ưu đãi về thuế, tín dụng nhằm thúc đẩy đổi mới sáng tạo thông qua việc tiếp nhận, chuyển giao công nghệ. Các chính sách ưu đãi về thuế, tín dụng cần được bổ sung và hoàn thiện nhằm thúc đẩy doanh nghiệp thực hiện các hoạt động nghiên cứu, giải mã, hoàn thiện và đổi mới công nghệ; đồng thời nên có những chính sách hỗ trợ riêng biệt về tín dụng cho các doanh nghiệp sản xuất ra các sản phẩm trọng điểm, có lợi thế cạnh tranh trong việc tiếp nhận công nghệ để đầu tư, mở rộng sản xuât, hiện đại hóa dây chuyền công nghệ tiếp nhận từ nước ngoài, từng bước nâng cao năng suất, chất lượng và năng lực cạnh tranh của các sản phẩm 
trên thị trường, nâng mức hỗ trợ, tài trợ, ưu đãi tín dụng cho các dự án nghiên cứu và sản xuất thử nghiệm các sản phẩm mà trong nước chưa sản xuất được, hoặc đã sản xuất được nhưng chất lượng chưa cao và chưa xuất khẩu được. Tiếp tục hỗ trợ tài chính từ nguồn ngân sách nhà nước và các nguồn vốn ODA cho các doanh nghiệp đổi mới công nghệ, được hưởng các ưu đãi khi tham gia Chương trình công nghệ cao, Chương trình phát triển tài sản trí tuệ, Chương trình nâng cao năng suất, chất lượng, Chương trình hợp tác song phương, Chương trình sản phẩm quốc gia và các chương trình quốc gia về khoa học và công nghệ khác. Cùng với đó là tăng cường hiệu quả hoạt động của Quỹ phát triển doanh nghiệp nhỏ và vừa, Quỹ Đổi mới công nghệ quốc gia, Quỹ phát triển khoa học và công nghệ,... qua đó tạo thêm nguồn vốn dài hạn, có lãi suất hợp lý cho các doanh nghiệp nhỏ và vừa đầu tư hoàn thiện và làm chủ công nghệ thông qua chuyển giao công nghệ.

\section{Kết luận}

Như vậy, Trung Quốc thực hiện chính sách nhập toàn bộ máy móc, thiết bị, dây chuyền sản xuất (chủ yếu từ Liên Xô cũ vào những năm 60 ), sau đó chuyển hướng chính sách sang nhập khẩu các công nghệ tiên tiến từ Nhật Bản và các nước Tây Âu nhằm nâng cao năng lực công nghệ sản xuất và tích lũy tri thức. Tiểp đến, Trung Quốc chuyển hướng sang chính sách nhập những phần chủ chốt của các thiết bị và công nghệ nhằm trang bị lại cho các nhà máy đã có sẵn công nghệ và cập nhật phát triển các sản phẩm. Đến nay, khi nền công nghiệp chế tạo đã phát triển mạnh, Trung Quốc lại chuyển đổi chính sách nhập khẩu công nghệ dưới hình thức mới, đó là cho phép các doanh nghiệp, tập đoàn lớn trên thế giới hình thành các cơ sở nghiên cứu và phát triển, chuyển giao công nghệ tại Trung Quốc. Cùng với tinh thần sáng tạo và phát triển năng lực nội sinh về khoa học và công nghệ, Trung Quốc đã tập trung nguồn lực để giải quyết được những vấn đề khó khăn, cấp bách về công nghệ do thực tiễn đặt ra trong việc làm chủ, sao chép và giải mã công nghệ nhập để tạo ra các công nghệ mới. Đặc biệt trong tình hình thiếu công nghệ, thiếu vốn, thiếu tài nguyên trong giai đoạn đầu của quá trình công nghiệp hóa, Trung Quốc đã xây dựng đội ngũ cán bộ khoa học và công nghệ nhiệt huyết, có trình độ, năng lực sáng tạo cao, đồng thời đã thể hiện được sự liên kết sáng tạo trong việc làm chủ công nghệ sản xuất dựa vào chất lượng nguồn lực và các hoạt động nghiên cứu và triển khai. Đây là các gợi ý có giá trị cho Việt Nam trong quá trình xây dựng, thực thi chính sách thúc đầy chuyển giao, làm chủ và nâng cao năng lực nội sinh công nghệ.

\section{Tài liệu tham khảo}

[1] Ministry of Science and Technology, Vietnam Science and Technology, (in Vietnamese), Science and Technology Publishing House, 2019.

[2] W.M Jin, The analysis of status quo and investigation on the cause of development of Chinese technology market, University of Science and Technology of China, 2009.

[3] National Agency of Science and Technology Information, World Science and Technology - Skills for innovation (in Vietnamese), Science and Technology Publishing House, 2017.

[4] National Science and Technology Information Center, China realizes its ambition to become a technology superpower (in Vietnamese), Hanoi, 2005.

[5] National Science and Technology Information Center, China's National Innovation System (in Vietnamese), Hanoi, 2009.

[6] J.M. Sun, X. Zhang, Z.W. Han, , The research on the development of Qingdao technology transaction market, Innovation Science and Technology, 189(11) (2015) 56-58,

[7] T.N. Ca, N.H. Xuyen, Science, technology and innovation in Vietnam: Current situation and policy solution, International Journal of Science and Research 9 (3) (2020) 1399-1403.

[8] P.X. Dung, Vietnam's technology and technology transfer: status and solutions (in Vietnamese), National Political Publishing House, 2017. 